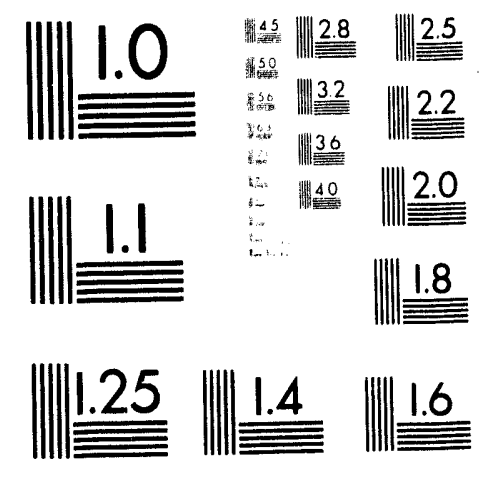



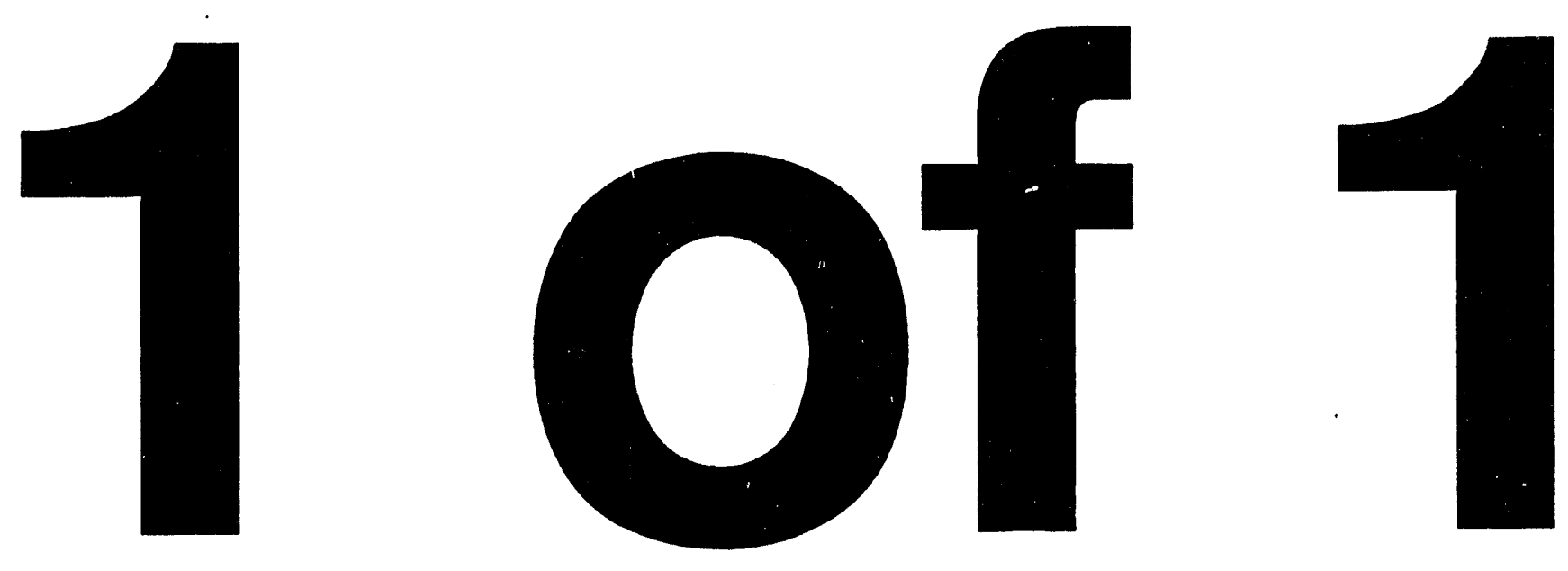


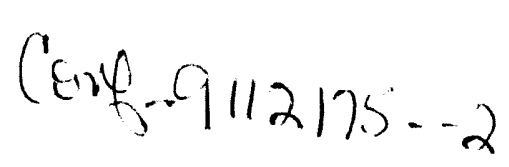

\title{
A NUMERICAL SIMULATION OF THE CATALINA EDDY
}

\author{
Kyozo Ueyoshi and John O. Roads \\ Scripps Institution of Oceanography \\ University of California, San Diego \\ La Jolla, CA 92093-0224 \\ and \\ Jordan Alpert, \\ National Meteorological Center \\ Washington, D.C. 20233
}

A shallow cyclonic eddy termed the Catalina Eddy has occasionally been observed during summer in the bight of southern California (Mass and Albright, 1989). The Catalina Eddy occurs within $\sim 100 \mathrm{~km}$ from the coastal mountains with a depth typically extending up to the marine inversion level of several hundred meters above sea level and a diameter on the order of 100-200 km (Clark and Dembek, 1991). The Catalina Eddy is produced by the interaction between the synoptic-scale northerly flow and the formidable topography along the southern California coast. A favorable synoptic situation that enhances the increased low-level climatological northerly flow along the central California coastline is the presence of the prominent east-west pressure gradient between the subtropical East Pacific high and the inland thermal low over California. Increased northerlies impinging on the San Rafael mountains north of Santa Barbara result in enhanced mesoscale lee troughing in the bight and establishment of a narrow ridge alongshore, leading to establishment of cyclonic vorticity in the bight.

This paper describes numerical simulations and predictions of a Catalina Eddy event with a highresolution multi-level limited area model. The model is initialized and forced at the lateral boundaries by the National Meteorological Center's (NMC) $2.5^{\circ} \times 2.5^{\circ}$ global objective analysis and also by NMC's medium range forecast model (MRF) 1-10 day forecasts. In our previous effort to simulate mesoscale disturbances such as the Catalina Eddy (Ueyoshi and Roads, 1991) the integrations were performed up to 1 model-day utilizing the NMC analysis as fixed lateral boundary conditions. In this paper we describe the results of continuous 5- to 7-day simulations of the Catalina Eddy event of 26-30 June 1988 (Mass and Albright, 1989) by utilizing time dependent lateral boundary conditions obtained from NMC's global objective analysis as well as NMC's MRF forecasts.

The three-dimensional fine mesh model is a moist hydrostatic primitive equation model with nonuniformly spaced $12 \sigma$-levels in the vertical. 'The horizontal resolution is about 10 times $\left(0.25^{\circ} \simeq 25 \mathrm{~km}\right)$ that of NMC's $2.5^{\circ} \times 2.5^{\circ}$ objective analysis. The model ntilizes a fourth-order accurate version of Arakawa's potential enstrophy and total energy conserving horizontal finite-difference scheme (Arakawa and Lamb, 1981). More details of the model are given in Ueyoshi and Han (1991) and Ueyoshi and Roads (1991).

Figure 1 shows a time series of the surface mean flow fields that evolved after the model was initialized and forced by the NMC analysis for 00 UTC 25 June 1988. The model was integrated continually for 7 modeldays. The lateral boundary conditions in the buffer zone surrounding the model domain were continually updated by linearly interpolating in time the twice-daily NMC analyses. Inside the model domain, however, the model physics alone determines the processes and the NMC analysis was not used. An eddy is seen to evolve within the southern California bight. Unlike a Santa Ana event described in Ueyoshi and Roads (1991), a Catalina Eddy event seems to require a relatively longer time $(\sim 12 \mathrm{~h})$ to develop to full intensity. We note that the intensity of the eddy at a mid-morning hour of 18 UTC (10 PST) is relatively weak compared with the eddy intensity at an evening hour of 06 UTC (22 PST), indicating that the formation and evolution of the eddy is also influenced by the diurnal characteristics of the ambient flow such as the stability of the near-surface air.

We also performed a series of the experiments utilizing NMC's MRF forecasts for the time period of this particular Catalina Eddy cvent. The MRF forecast data consists of 1-10 day forecasts (once-daily at 00 U'TC) of temperature, relative humidity and wind components at the 12 mandatory pressure levels made by 


\section{DISCLAIMER}

This report was prepared as an account of work sponsored by an agency of the United States Government. Neither the United States Government nor any agency thereof, nor any of their employees, makes any warranty, express or implied, or assumes any legal liability or responsibility for the accuracy, completeness, or usefulness of any information, apparatus, product, or process disclosed, or represents that its use would not infringe privately owned rights. Reference herein to any specific commercial product, process, or service by trade name, trademark, manufacturer, or otherwise does not necessarily constitute or imply its endorsement, recommendation, or favoring by the United States Government or any agency thereof. The views and opinions of authors expressed herein do not necessarily state or reflect those of the United States Government or any agency thereof. 
NM('s global spectral model (MRF model). The skill of the MRF forecasts of those surface variables was assessed by Roads et al. (1991) for the period of 1 June 1988 to 31 May 1990.

Shown in Fig. 2 are a series of the surface mean flow ficlds that developed after the model was initialized and forced by the MRF fnrecasts made at 00 UTC 24 June 1988 for 00 UTC 25 June - 00 UTC 30 June 1988. Therefore, at the time of the model initialization the 24 -h forecast made at 00 UTC 24 June for 00 UTC 25 June was utilized. The lateral boundary conditions were subsequently specified by interpolating linearly in time the MRF forecasts available at 24 -h intervals. Thus, at the end of this 5 -model-day integration the model was utilizing the 6-day forecasts as the lateral boundary conditions. An eddy is observed to develop in the bight, although the vortex is not as intense as when the NMC andlysis is used and seems to be confined near the sea shore. This suggests that present-day operational forecast models are capable of predicting the large-scale flow responsible for mesoscale disturbances, the Catalina Eddy in this particular case, for at least 3 days in advance.

Arother experiment with MRF forecasts was performed utilizing the 3- to 8-day forecasts made at. 00 UTL: 22 June for 00 UTC 25 June - 00 UTC 30 June. The surface flow patterns do not show a discernable eddy as in the previous experiments, although we detect an indication of eddy formation (Fig. 3).

Figure 4 illistrates the 24-h isallobaric charts ending at 06 UTC 27 .Tune and 06 UTC 28 June for the three simulations described above. The model results from the 7 -day simulation with the NMC analyses compare favorably with observations (Mass and Albright, 1989). In the 24-h isallobaric patterns for the 5-day experiment initialized with the 24-h MRF forecasts the onset of the event is also clearly seen, although it is not as distinctive as in the NNC case. However, the isallobaric cliarts for the second MRF simulation initialized with the $72-\mathrm{h} M \mathrm{MF}$ forecasts do not indicate the characteristic pressure changes found in the ohscrvations and also in the two experiments described ahove. It suggests that beyond $\sim 3$ days ahead the MRF forecasts seems to fail to predict synoptic-scale conditions that are essential to the development of this particular eddy event.

Clark and Dembek (1991) suggested that the formation of the Catalina Eddy probably cannot be characterized by a single value of the Froude Number. An example consistent with their assertion is the flow pattern evolved at 06 U'TC 01 July for the NMC case (not shown) which exhibits a well-developed eddy. The flow over Temblor Range north of San Rafael mountains at this hour is southwesterly, rather than climatological northwesterly, indicating the complexity of the mechanism for eddy formation.

In summary, we found that the NMC objective analysis can a useful tool for obtaining fine-scale regional climatology when used as initial and boundary conditions for a high-resolution mesoscale model. We also found that the MRF outputs can be used for reasonably accurate predictions of mesoscale disturbances up to $\sim 3$ days when utilized as lateral boundary forcing of a fine-scale model. We intend to further investigate the mechanisms for the eddy formation and dissipation by atilizing the high-resolution mesoscale model.

\section{REFERENCES}

Arakawa, A., and V.R. Lamb, 1981: A potential enstrophy and energy conserving scheme for the shallow water equations. Mon. Wen. Rev., 109, 18-36.

Clark, J., and S. Dembek, 1991: The Catalina Eddy event of July 1987: $\Lambda$ coastally trapped mesoscale response to synoptic forcing., Mon. I'ea. Rev., 119, 1714-1735.

Mass, C., and M.D. Albright, 1989: Origin of the Catalina Eddy. Mon. Wea. Rev., 117, 2406-2436.

Roads, J.O., K. Ueyoshi, S.C. Chen, J. Alpert and F. Fujicka, 1991: Medium-range fire weather forecasts. To appear in International $J$. of Wildland Fire.

Ueyoshi, K, and Y.-J. Han, 1991: A three-dimensional simulation of airflow and orographic rain over the island of Hawaii. J. Meteor. Soc. Japan., 69, 127-152.

Ucyoshi, K. and J.O. Roads, 1991: A preliminary simulation of western U.S. weather and climate. Proc. of the $1.5 \mathrm{~h}$ Annual Climnte Dingnostics W'orkshop. 29 Oct.-2 Nov. 1990, Asheville, Climate Analysis Centor/NMC, NOA , 439-444. 


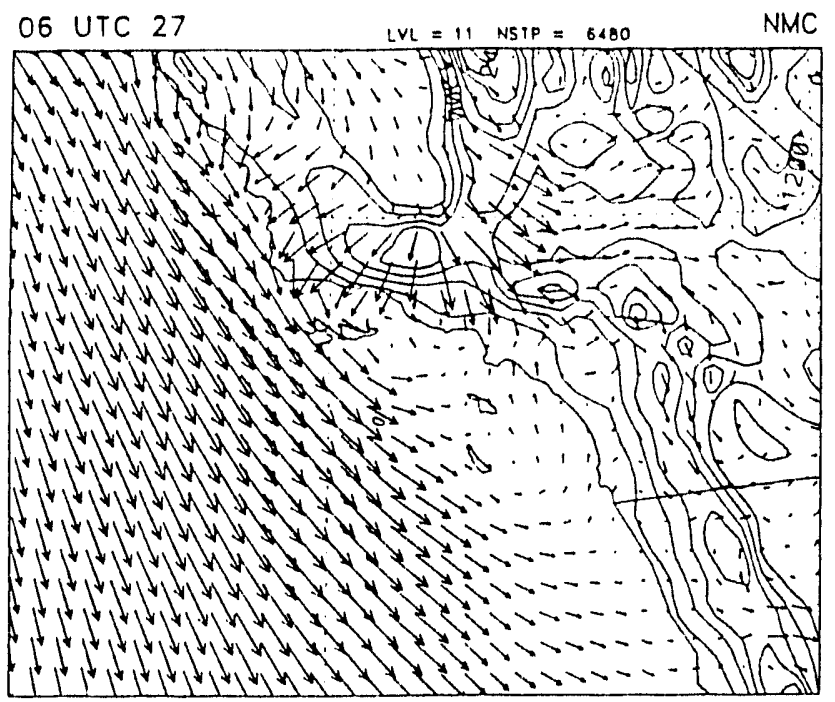

06 UTC 28

LVL $=11$ NSTP $=9360$

NMC

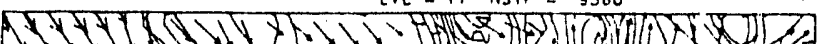

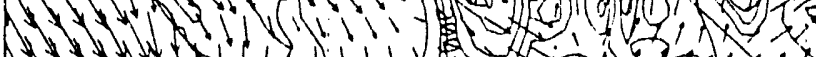

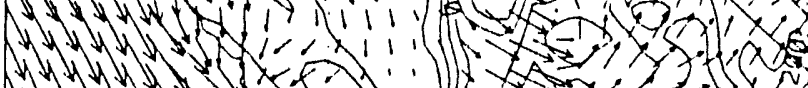

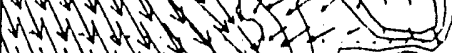

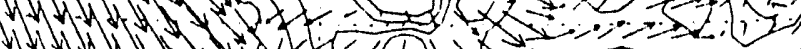

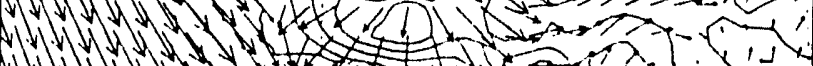

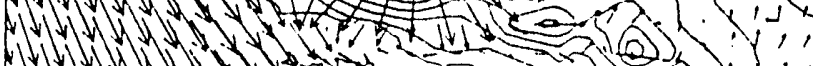

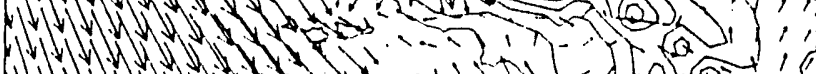

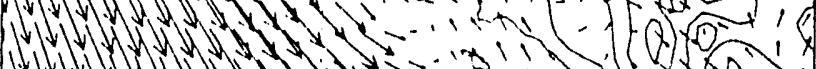

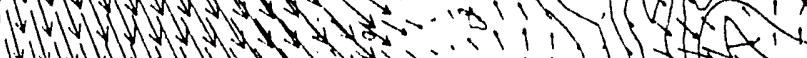

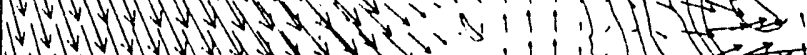

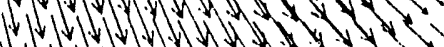

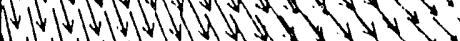

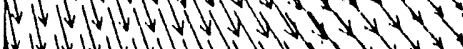

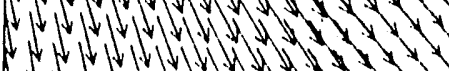

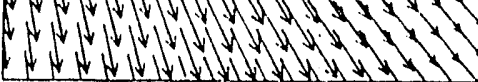

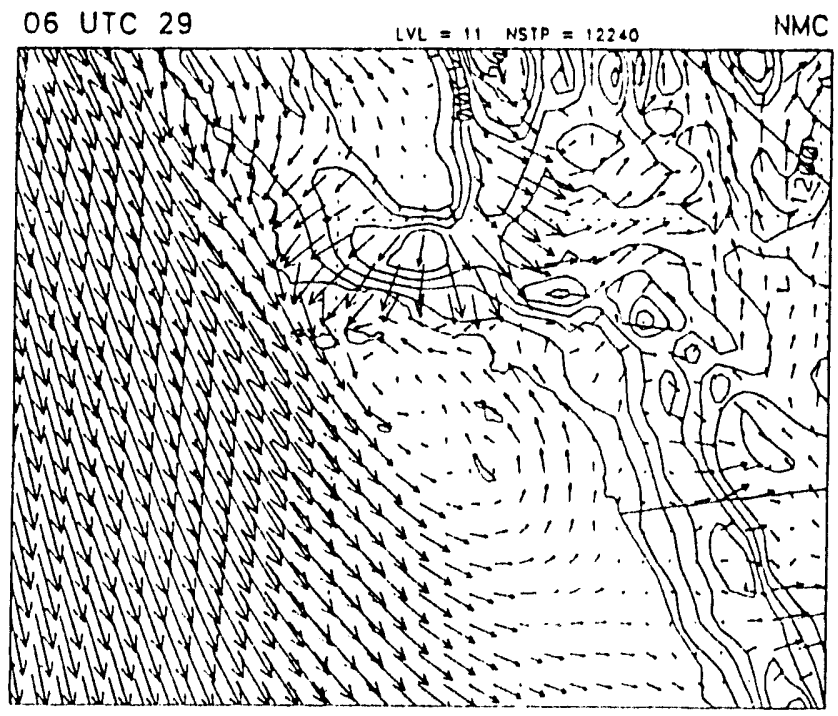

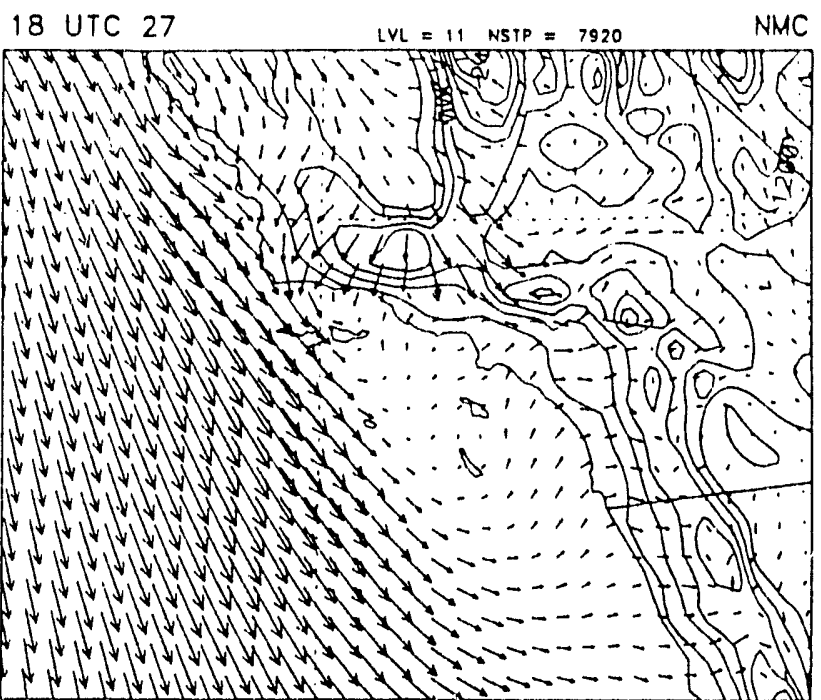

TVL $=11$ NSIP = 10000 NMC
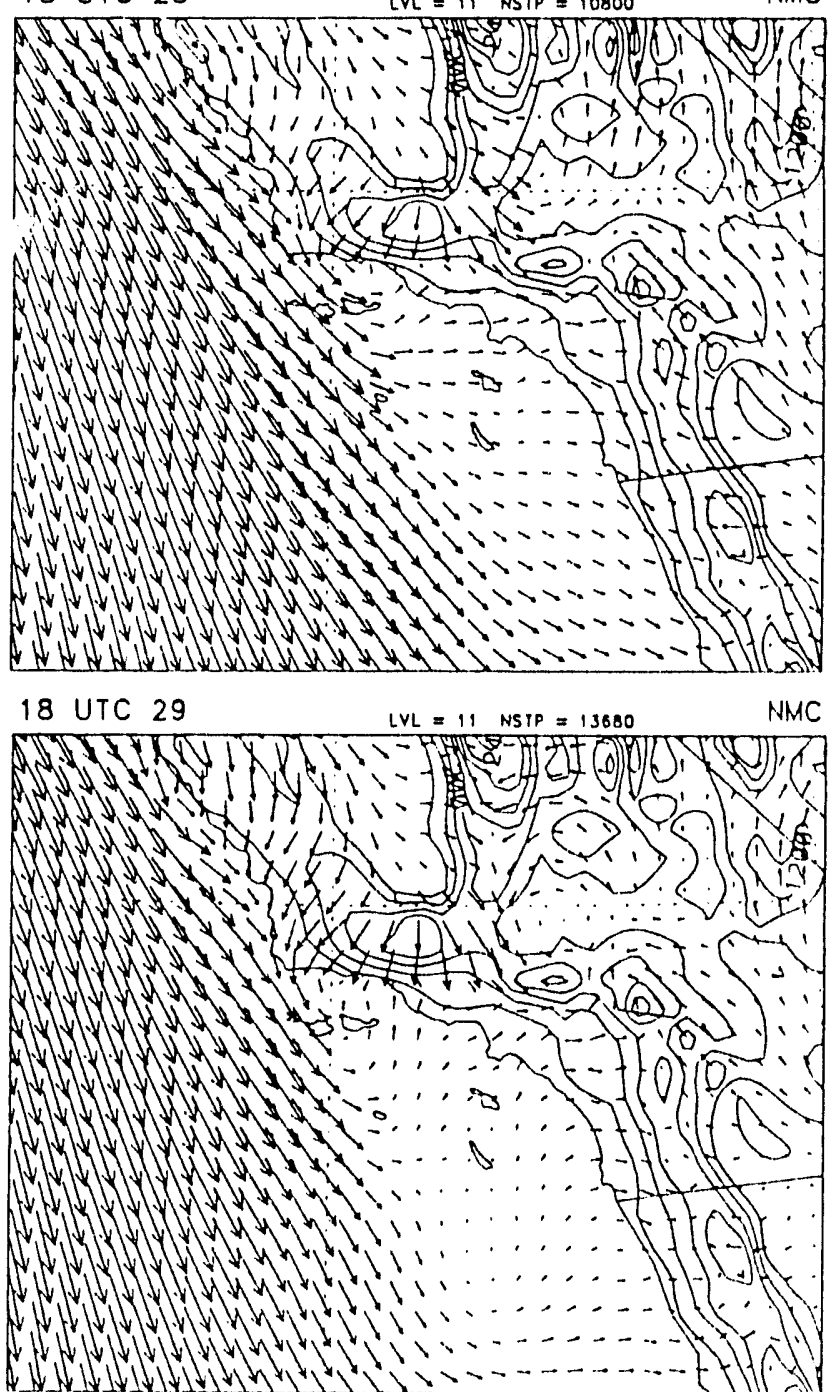

Fig. 1. Folution of simmlated wind fields at $\sim 100 \mathrm{~m}$ above the carth's surface for somihrm Coliformia at 06 U'TC and 18 U'TC, 26-30 June 1988. NMC's large-scale objective analyses were utilized as intial and lateral boundary conditions. $\Lambda$ wind vector with a length of nne nast-west grid length corresponds to $\sim 6.2 \mathrm{~ms}^{-1}$. 

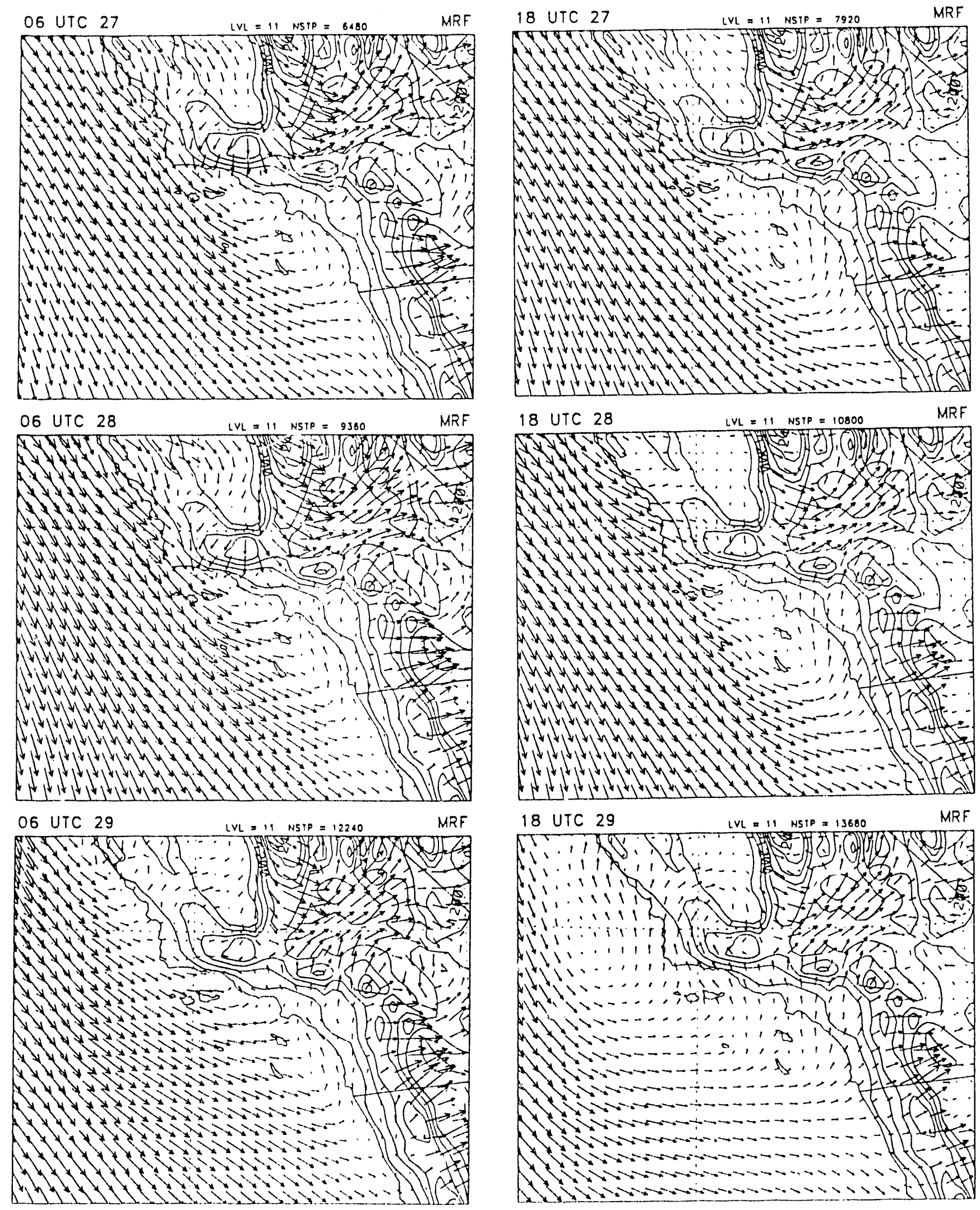

Fig. 2. As in Fig. 1 except that the 1- 1. 6-lay MIRF forecasts made at 00 U'TC; 24. June 1988 for 0n U'TC: 25-30 June 1988 were used. 

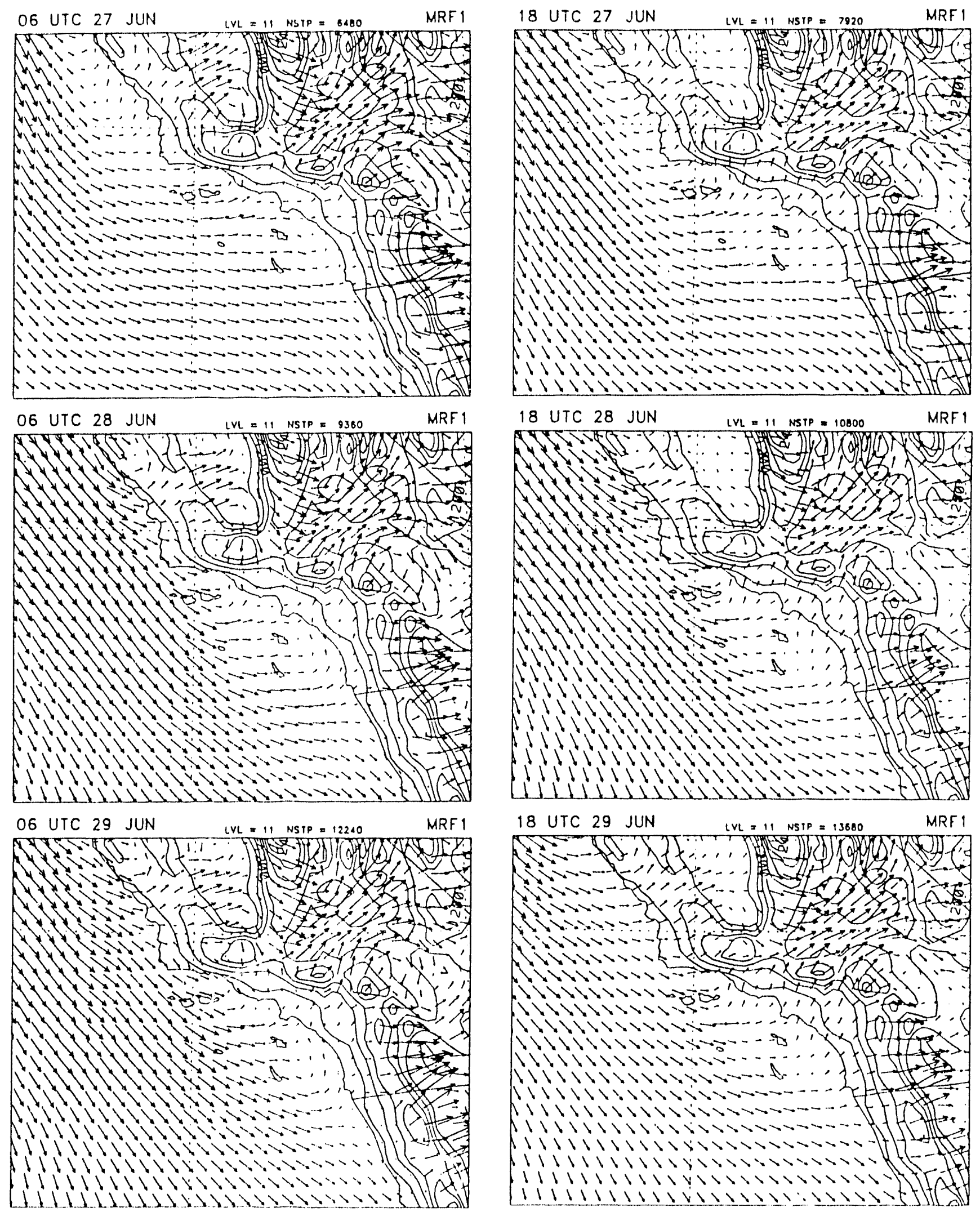

Fig. 3. As in Fig. 1 excent that the 3- to 8-day MRF forecasts made at 00 U'TC: 22 June 1988 for 00 1]'T(: 25-30 June 1988 were used 

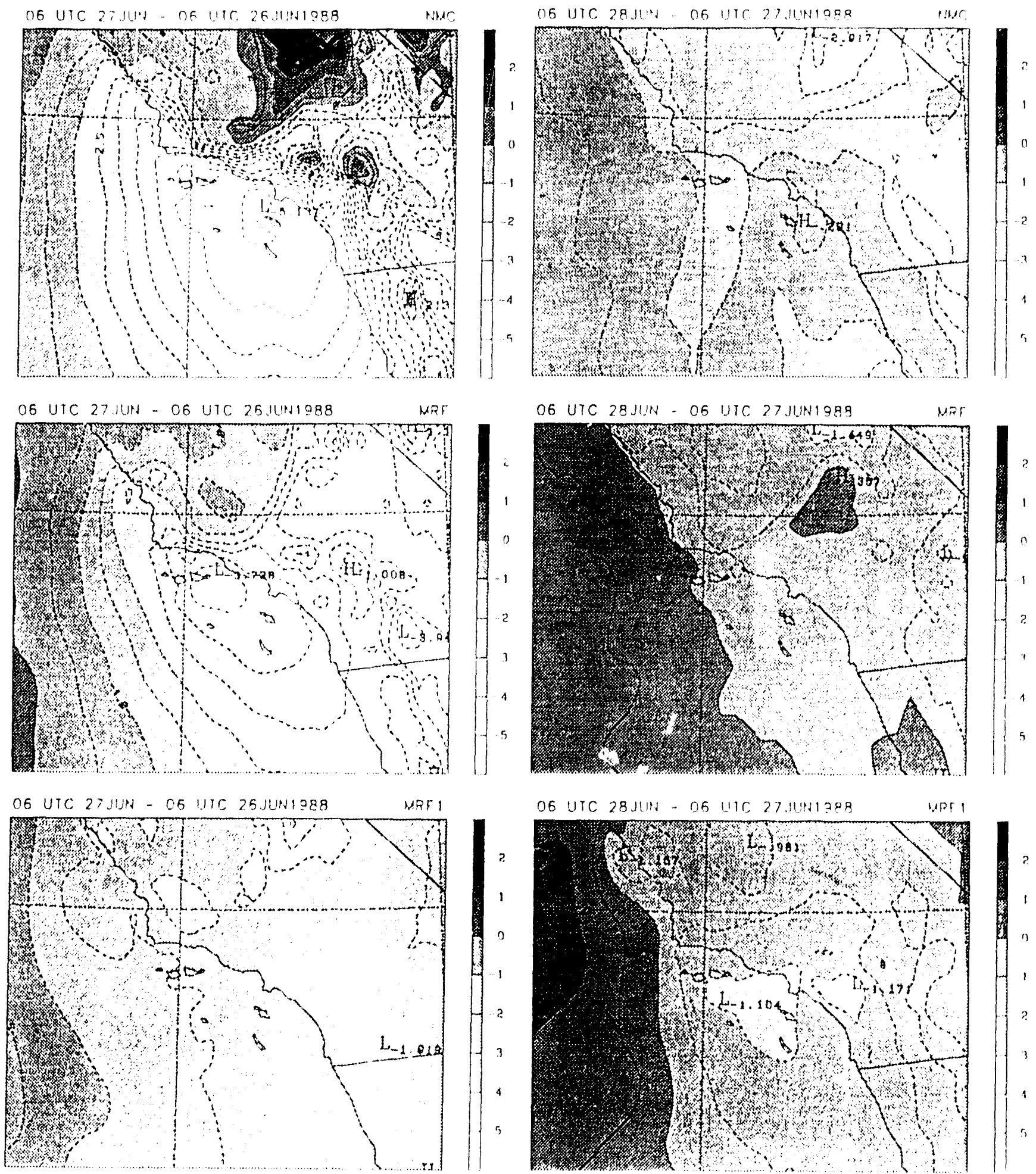

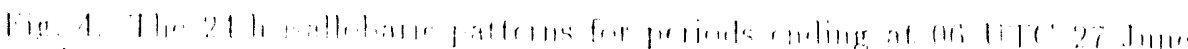

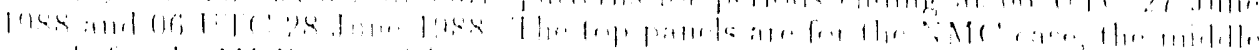

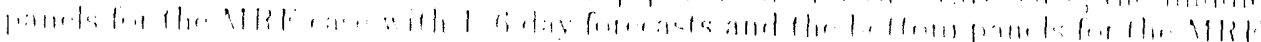

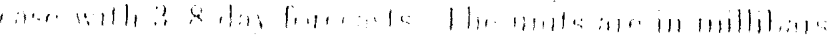



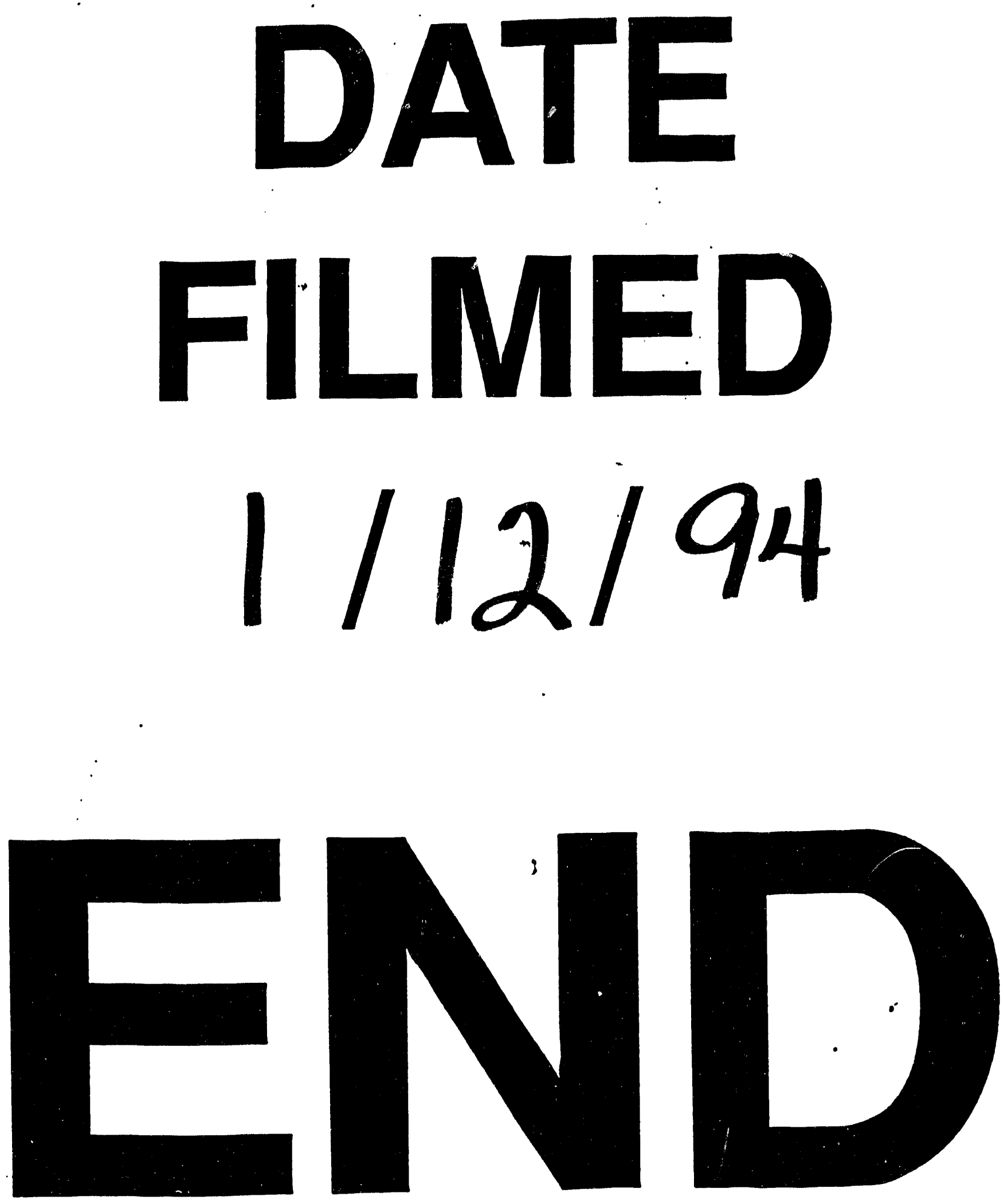
